\title{
FRANCISCO ANTONIO LACAZ NETTO (1911-1991): BREVE BIOGRAFIA ${ }^{1}$
}

\author{
Angelica Raiz Calabria \\ Centro Universitário Hermínio Ometto - Uniararas - Brasil
}

(aceito para publicação em novembro de 2016)

\begin{abstract}
Resumo
O presente trabalho tem como objetivo acrescentar informaçãoes à História da Matemática e apresentar uma breve biografia do professor Francisco Antonio Lacaz Netto, descrevendo sua formação, sua carreira docente, suas principais obras e homenagens, privilegiando a sua trajetória no Instituto Tecnológico de Aeronáutica (ITA) e a sua dedicação como professor, a qual o torna, segundo nossas perspectivas, um educador matemático. A fim de alcançar tal objetivo, analisamos seu acervo pessoal e realizamos entrevistas com amigos e familiares.
\end{abstract}

Palavras-chave: Matemática, História, Biografia, Professor Lacaz Netto, História da Matemática no Brasil.

\section{[FRANCISCO ANTONIO LACAZ NETTO (1911-1991): BRIEF BIOGRAPHY]}

\begin{abstract}
This paper aims to add information to the History of Mathematics in Brazil and It presents a brief biography about the Professor Francisco Antonio Lacaz Netto, describing his professional training, university lecturer career, major works and honours, highlighting his career at Instituto Tecnológico de Aeronáutica (ITA) and also his dedication as professor which present him as Math Educator. In order to accomplish such a goal, we analized the personal collection this professor and conducted interviews with friends and family.
\end{abstract}

Keywords: Mathematics, History, Biography, Professor Lacaz Netto, History of Mathematics in Brazil.

\footnotetext{
${ }^{1}$ Este trabalho apresenta informações parciais da pesquisa de doutorado da autora intitulada "Francisco Antonio Lacaz Netto (1911-1991): um estudo biográfico", realizada sob a orientação do Prof. Titular Sergio Roberto Nobre na Unesp, campus de Rio Claro, defendido no ano de 2015.
}

RBHM, Vol. 16, n 32, p. 1-17, 2016 


\section{Introdução}

Este trabalho baseia-se no tema Biografias, o qual, em relação às pesquisas em História da Matemática do Brasil, ainda é um campo aberto e inexplorado. Com isso, a trajetória de vida de alguns educadores ou pesquisadores matemáticos acaba passando despercebida e, muitas vezes, as informações encontradas são oriundas de materiais e fontes com dados não fundamentados. Isto se torna desfavorável ao movimento científico, pois as biografias são muito utilizadas no meio acadêmico e, também, possibilitam conhecermos os principais aspectos, trabalhos e episódios de vida de personagens que fizeram parte da comunidade científica, particularmente, a que envolve a matemática brasileira. Desta forma, torna-se necessário biografar estas personagens que fizeram parte desse cenário, pois sem estas informações, muitas pesquisas ficam incompletas, o que pôde ser constatado com o relato de Baraldi (2003) em sua tese de doutorado, na qual, com o intuito de acrescentar dados sobre alguns professores, não encontrou nenhuma referência e comenta que

"Os depoentes dessa nossa pesquisa fazem inúmeras referências a nome de lugares e personagens que, em seus registros, despontam como importantes, como apoio à lembrança, como referências de um tempo e espaços vividos e, ainda, como tributo, como homenagem [...] Algumas personagens são bastante conhecidas, outras nem tanto. Algumas sequer tem registro além daquele exclusivo das memórias dos depoentes, manifestado pela citação. Buscamos, quando possivel, complementar as referências, ainda que de modo breve - de modo muitíssimo breve, em alguns casos - visto que, por um lado, não poderíamos negligenciá-las. Essas apoucadas sínteses biográficas presentes em notas de rodapé, estão longe de fazer justiça à atuação das personagens que compõem a memória dos depoentes." (BARALDI, 2003, p. 14).

Averiguamos, então, com este relato, a ausência de trabalhos no que diz respeito ao tema Biografias e, neste sentido, o presente artigo tem a finalidade de apresentar uma breve biografia sobre o professor Francisco Antonio Lacaz Netto, que foi considerado um grande didata, autor de livros didáticos do período das Reformas Capanema e Simões Filho, preocupado com a educação e o aprendizado de seus alunos, além de ser um amante de sua profissão e da Matemática. Além disso, Lacaz Netto foi professor do Instituto Tecnológico de Aeronáutica (ITA), instituição na qual trabalhou até sua aposentadoria. Fez várias contribuições a este instituto, principalmente, no que se refere à constituição inicial do quadro docente do Departamento de Matemática, auxiliando na escolha dos professores para compor este departamento. No mais, como professor, foi estimado pela maioria de seus alunos.

Para que pudessemos realizar esta investigação buscamos, analisamos e interpretamos documentos históricos, os quais estão relacionados com o acervo pessoal do professor Francisco Antonio Lacaz Netto e, também, depoimentos e entrevistas com pessoas próximas deste nosso biografado. E em meio a esse compêndio de informações, documentos, registros e fontes, procuramos escrever fielmente os aspectos vividos por 
Lacaz Netto, ou seja, buscamos "[...] reunir o maior número possível de conhecimento sobre um personagem histórico, a fim de aproximar, tanto quanto possível, da sua verdade viva, com o máximo de precisão, de autenticidade e probidade" (ORIEUX, 1986, p. 33).

Nesta perspectiva, exibiremos, a seguir, a trajetória de vida do professor Lacaz, procurando resgatar o passado por meio de sua biografia, fazendo aparecer o professor Francisco Antonio Lacaz Netto como verdadeiro personagem da História da Matemática do Brasil.

\section{Informações Pessoais}

"Francisco Antonio Lacaz Netto, o Chico, foi indiscutivelmente, um dos homens mais completos que conheci em minha vida. Caráter ilibado, chefe de família exemplar, culto, professor de matemática de raros méritos, de uma integridade sem par, enérgico, de uma bondade sem limites, auxiliava a todos sem fazer alardes. Não proclamava suas virtudes".

- Carlos da Silva Lacaz (irmão do professor Lacaz)

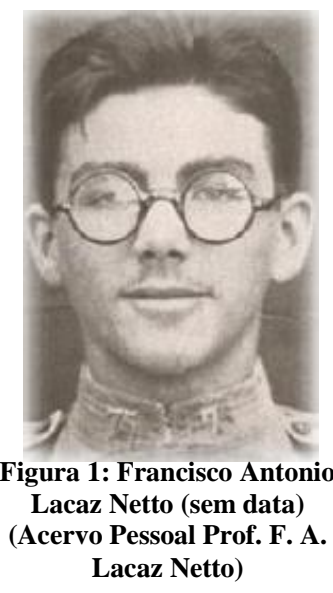

A família Lacaz é de origem francesa, especificamente, da cidade de Cahors, situada às margens do rio Lot. Antonio Roufin Lacaze, bisavô do professor Lacaz, veio ao Brasil em 1819, onde residiu no Largo do Carioca e, posteriormente, em Cantagalo, ambas as cidades localizadas no estado do Rio de Janeiro. Em 1831casou-se com Agatha Yeca Lacaze, de origem suíça, com quem teve três filhos: João, Francisco e Ernesto. Dos três, Francisco foi avô paterno do professor Lacaz.

Francisco Antonio Lacaz casou-se com Emília Adelaide da Silva Lacaz e dessa união tiveram 11 filhos: Maria, Ernesto, Elvira, Maria, Lidia, Dalila, Etelvina, Américo, Oscar, , Rogério e Cleópatra. Dos 11 filhos, destacamos Rogério da Silva Lacaz, pai do professor Lacaz, que se casou com Judith Limongi Lacaz. Desse casamento, nasceram Rogério, Emília, Francisco, Paulo,

Carlos e José. O Francisco é o então professor Francisco Antonio Lacaz Netto.

Nesse sentido, professor Lacaz nasceu em Guaratinguetá, cidade do interior de São Paulo, aos 06 de fevereiro de 1911. Cresceu em um ambiente simples, numa casa que a chamavam de Chalé da Estação, por se situar em frente à Antiga Estação Ferroviária de Guaratinguetá.

No decorrer da investigação desta pesquisa, não encontramos informações sobre sua infância e adolescência, porém, averiguamos que casou-se, também, na cidade de Guaratinguetá no dia 30 de dezembro de 1933, com a Sra. Silvia Maria D’Alessandro e desta união tiveram dois filhos, Luiz Roberto e Maria Helena da Silva Lacaz. 
Professor Lacaz, após casar-se, foi a São Paulo e passou a lecionar em vários colégios e instituições e, apenas depois, estabeleceu-se em São José dos Campos, onde lecionou no ITA e permaneceu até sua aposentadoria.

No dia 13 de julho de 1991, professor Lacaz faleceu e deixou uma rica herança de sabedoria e estima entre os seus amigos, alunos e familiares.

"[...] perdemos sua convivência, sua imagem simples, sóbria e austera do Mestre mas não perdemos sua sabedoria. Imaginamos que sua imagem envolveu-se na neblina da eternidade dos tempos, seus ensinamentos serão perenes aos milhares de alunos e por certo transmitirão a outras gerações de jovens o saber legado pelo emérito Prof. F. A. Lacaz Netto como assim foi conclamado pela Congregação dos Professores do ITA" (TEIXEIRA, 1996, p. 8).

Após destacarmos, brevemente, alguns aspectos pessoais do professor Lacaz, nos próximos itens, apresentaremos informações sobre sua formação, sua carreira docente e o seu papel de professor e administrador nas instituições que trabalhou, destacando, dentre elas, o Instituto Tecnológico de Aeronáutica.

\section{Formação}

"[...] antiga Escola Normal de Guaratinguetá, onde tive a honra de me diplomar, e aprendi solidamente os fundamentos da Matemática e a ter gosto pela Aritmética".

- Francisco Antonio Lacaz Netto.

Neste tópico relataremos a formação do professor Lacaz Netto, destacando quais instituições realizou os seus estudos, tanto no Ensino Básico quanto no Superior e, também, outros cursos realizados após sua formação.

Assim, de acordo com os seus certificados de certidão de Exames Finais, professor Francisco Antonio Lacaz Netto realizou parte de seus estudos básicos no Ginásio Nogueira da $\mathrm{Gama}^{2}$, localizado em Guaratinguetá. Não encontramos informações de quando ele iniciou seus estudos nesse estabelecimento de ensino, apenas documentos comprovando os três primeiros anos do ginásio.

Posteriormente, formou-se como Professor Normalista pela Escola Normal de Guaratinguetá $^{3}$ no ano de 1928. Após a conclusão do magistério, realizou um curso de

\footnotetext{
2 Colégio criado pelo educador Lamartine Delamare Nogueira da Gama, na capital de São Paulo. Posteriormente, foi transferido para Jacareí, interior de São Paulo, e, depois, em 1920, para Guaratinguetá. Atualmente, denominase Faculdades Nogueira da Gama, onde funciona o Colégio e oferece os cursos de graduação em Administração, Ciências Contábeis e Pedagogia.

${ }^{3}$ Esta escola foi criada em 1902, no governo de Bernardino de Campos e, na época, foi uma das seis escolas complementares do estado de São Paulo, com a finalidade de formar professores para o antigo magistério primário e é denominada atualmente Escola Estadual "Conselheiro Rodrigues Alves".
} 
farmacêutico na Escola de Farmácia e de Odontologia de Itapetininga ${ }^{4}$, o qual concluiu em novembro de 1930.

Além desse curso de farmacêutico, Lacaz Netto fez mais dois cursos de ensino superior, o de Engenheiro Geógrafo pela Escola Politécnica da Universidade de São Paulo, concluído em 1932. Após este curso, ingressou na primeira turma de Matemática, em 1934, da Faculdade de Filosofia, Ciências e Letras da Universidade de São Paulo (FFCL - USP), graduando-se em licenciatura no ano de 1936, na mesma turma de reconhecidos matemáticos como Cândido Lima da Silva Dias, Fernando Furquim de Almeida, Edson Farah e Benedito Castrucci, que foram professores assistentes da FFCL-USP e, posteriormente, catedráticos. Este curso de Matemática era destinado à formação de professores com duração de três anos, apresentando as seguintes disciplinas: Geometria (analítica e projetiva), Análise Matemática, Física Geral e Experimental, Cálculo Vetorial, Mecânica Racional e Geometria.

Professor Lacaz não realizou cursos de pós-graduação, no entanto, teve uma experiência profissional no exterior. Entre os anos de 1958 e 1959, foi à Itália para estudar e não realizar curso regular. Lá estudou Teoria das Funções Analíticas de Variáveis Complexas sob a orientação do professor Enzo Martinelli (1911-1999) ${ }^{5}$, no Instituto Superior de Matemática da Universidade de Roma e foi auxiliado pelo Conselho Nacional de Pesquisas (CNPq).

Concluímos que a formação desse professor consiste em, além de seus estudos básicos, cursos de Farmácia, Engenharia Geográfica e Matemática e, também, a realização de um curso de especialização na Itália. Após apresentarmos esta formação, iremos enfatizar a função que exerceu durante sua vida, que foi atuar como professor.

\section{Carreira Docente}

"Sua palavra eloquente continua nas salas de aulas, levando saber à juventude. Autêntico educador."

- Carlos da Silva Lacaz (irmão do professor Lacaz Netto)

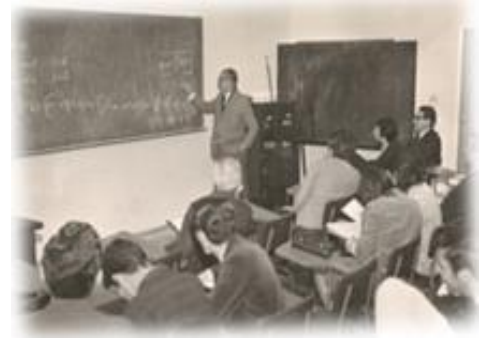

Figura 2: Prof. Lacaz Netto em aula (sem data) (Acervo Pessoal Prof. F. A. Lacaz Netto)

Uma das satisfações de Lacaz Netto era lecionar e um dos destaques deste artigo é relatar a sua característica como educador. Apesar de termos relatado que se formou como engenheiro e farmacêutico, a sua vocação profissional sempre foi a de ser professor.

Assim, sua carreira docente iniciou no Colégio "Nogueira da Gama" e na Escola de Comércio "Antônio Rodrigues Alves", ambas de

${ }^{4}$ Esta escola foi criada em 1921 e funcionou até o ano de 1937, na era do governo de Getúlio Vargas.

${ }^{5}$ Matemático italiano que atuou na área de Teoria das Funções de Várias Variáveis Complexas e é conhecido pelo seu trabalho em teoria de representações integrais para funções holomórficas de várias variáveis.

RBHM, Vol. 16, n 32, p. 1-17, 2016 
ensino básico e localizadas na cidade de Guaratinguetá, interior de São Paulo.

Posteriormente, foi lecionar na cidade de São Paulo. Uma das escolas paulistanas em que possivelmete iniciou suas instruções foi a Cruz Azul de São Paulo (atualmente Complexo Hospitalar Cruz Azul de São Paulo, uma instituição filantrópica brasileira, relacionada cultural e historicamente à Polícia Militar do Estado de São Paulo) como professor de Matemática do "Curso de Preparatórios da Cruz Azul", nomeado em 1931. Também lecionou na Força Pública do Estado de São Paulo, no Centro de Instrução Militar (hoje, denominado Academia de Polícia Militar do Barro Branco) durante o período de 1933 a 1939.

Ainda na cidade de São Paulo, lecionou no Liceu Pan-Americano para os Cursos Complementares Pré-Politécnico e Pré-Médico, no período de 1938 a 1942, encerrando suas atividades nesse colégio em 1943. Outra instituição que trabalhou, em 1937, foi o Colégio Santa Inês para o Curso Secundário (Colégio Clássico e Científico). Exerceu docência, também, na Escola Caetano de Campos (hoje Escola Estadual Caetano de Campos) em 1940, e no Ginásio Saldanha da Gama desde sua fundação até, provavelmente, o ano de 1943. Além destes colégios, trabalhou nos Colégios Bandeirantes e Danti Alighieri, possivelmente no período de 1942 a 1949.

Professor Lacaz também atuou no Ensino Superior e lecionou nas seguintes instituições:

- Na Escola Politécnica da Universidade de São Paulo, onde iniciou na 3a Seção do Colégio Univeristário, em 1937. Neste mesmo ano, foi professor substituto da cadeira de "Complementos de Matemática". Posteriormente, de 1942 a 1944, foi nomeado para reger a cadeira "Complementos de Geometria Analítica e Projetiva".

- Na Seção do Colégio Universitário anexa à Faculdade de Medicina Veterinária, também da Universidade de São Paulo, foi professor de Matemática, em 1942.

- Na Faculdade de Engenharia Industrial da Pontifícia Universidade Católica de São Paulo (PUC-SP), foi catedrático de "Geometria Analítica e Nomografia".

- Na Faculdade de Filosofia, Ciências e Letras do Instituto Mackenzie (hoje denominada Universidade Presbeteriana Mackenzie), em São Paulo, foi catedrático de "Geometria".

- Na Faculdade de Engenharia de Guaratinguetá (FEG), foi o primeiro professor de Análise Matemática, no período de maio de 1966 à agosto de 1967. Destacamos que professor Lacaz auxiliou na criação da FEG em 1966. Foi responsável por convidar professores para ministrar aulas nesta faculdade, muitos destes professores faziam parte do corpo docente do ITA.

Portanto, este professor iniciou sua carreira docente em Guaratinguetá e, em seguida, foi a São Paulo, capital, lecionando em várias instituições de ensino, entre elas escolas de ensino básico e superior, durante os anos de 1931 a 1949. Nesta trajetória, pôde acrescentar à sua carreira ampla experiência e cumpriu seu papel de professor com eficácia, pois era um professor querido e sua maneira de ensinar agradava o público discente. 
Por fim, recebeu o convite de um colega e professor da Escola Politécnina da USP, Paulus Aulus Pompéia (1911-1993) ${ }^{6}$, o qual referia-se a lecionar e auxiliar na seleção de professores para o Departamento de Matemática do Instituto Tecnológico de Aeronáutica, instituto que iniciaria suas atividades na cidade de São José dos Campos, interior de São Paulo, em 1950.

Assim, relatamos o início da carreira docente do professor Lacaz, porém, apresentaremos, a seguir, a continuidade desta carreira, no local onde trabalhou e se dedicou profissionalmente por mais tempo, sendo não somente professor mas, também, chefe de departamento e reitor, local este que permaneceu além de sua aposentadoria.

\section{O ITA}

"Mas afinal o que é o ITA? É uma escola de engenharia pioneira, é a Escola de Engenharia que o Ministério da Aeronáutica mantém aqui em Sào José dos Campos [...] uma escola diferente de características próprias".

- Francisco Antonio Lacaz Netto

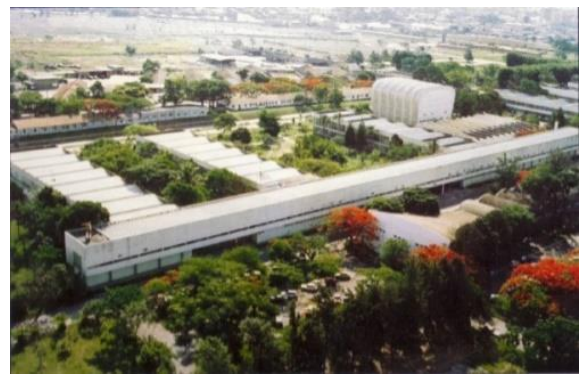

Figura 3: ITA 2000

(INSTITUTO..., 2000, p. 2-3)

O Instituto Tecnológico de Aeronáutica (ITA) foi idealizado pelo então Coronel Aviador Casimiro Montenegro Filho (1904-2000) ${ }^{7}$, no modelo e na estrutura do Massachussetts Institute of Technology (MIT), dos Estados Unidos. Suas atividades inciaram-se na Escola Técnica do Exército, situada no Rio de Janeiro e transferidas para São José dos Campos, interior de São Paulo, em 1950. Inicialmente, o primeiro curso deste instituto foi o de Engenharia Aeronáutica, nas especialidades de interesse a aviação brasileira em geral e para a Força Aérea Brasileira. Depois de transferido a São José dos Campos, o ITA implantou os cursos de Engenharia Eletronica em 1951, de Engenharia Mecânica em 1962 (transformado em Engenharia Mecânica-Aeronáutica em 1975), de Engenharia de Infraestrutura Aeronáutica em 1975 (transformada em Engenharia Civil-Aeronáutica em 2007) e de Engenharia de

\footnotetext{
${ }^{6}$ Físico que criou um método para medir a velocidade inicial de um projétil com o intuito de determinar o poder explosivo da pólvora avaliando o alcance que este projétil utilizava. Trabalhou no Instituto de Eletrotécnica da Politécnica da USP, depois no Departamento de Física e Química do ITA, estruturando o quadro docente, no qual permaneceu até sua aposentadoria. Posteriormente, assumiu a cadeira de Física na Faculde de Arquitetura e Urbanismo da USP (FAU-USP) e encerrou sua carreira profissional como Assessor Científico Cultural do Instituto de Pesquisas Tecnológicas.

7 Este personagem pertence à História da Aviação Brasileira e graduou-se na primeira turma do curso de Engenharia Aeronáutica na Escola Técnica do Exército, atual Instituto Militar de Engenharia. Participou ativamente da Revolução de 1930 e criou o Correio Aéreo Nacional. Encerrou sua carreira com a patente honorífica de Marechal do Ar.
} 
Computação em 1989, o mais recente, de Engenharia Aeroespacial, que foi implantado em 2010. Também possui Pós-Graduação Stricto e Lato Senso.

Neste instituto existem as Divisões Acadêmicas, distribuídas da seguinte forma: Ciências Fundamentais, Engenharia Aeronáutica, Engenharia Eletrônica, Engenhaira Mecânica-Aeronáutica, Engenharia Civil e Ciência da Computação. Dentre estas, a de Ciências Fundamentais é estruturada pelos Departamentos de Física, de Humanidades, de Química e de Matemática. Para este trabalho, versaremos, especificamente sobre o Departamento de Matemática.

Desta forma, quando o ITA foi criado, os primeiros professores a serem contratados eram estrangeiros, dentre eles destacamos o professor e matemático Francis Dominic Murnaghan $(1893-1976)^{8}$, quem ficou responsável pelo Departamento de Matemática. Além dos professores estrangeiros, foram contratados também, professores brasileiros, sendo um deles o nosso biografado, o professor Francisco Antonio Lacaz Netto, o primeiro a constituir o quadro docente do Departamento de Matemática do ITA.

Em 1950, foi contratado como professor associado e instalou-se com sua família no H17, apartamento 102, residência dos professores no campus do Centro Técnico de Aeronáutica, um direito ${ }^{9}$ do professor contratado. Assim, professor Lacaz passava a lecionar em um dos mais novos institutos de engenharia do Brasil. Porém, no decorrer de sua trajetória neste instituto, professor Lacaz exerceu outras atividades, uma delas foi a de auxiliar na constituição do quadro docente do Departamento de Matemática.

Como expomos anteriormente, o responsável por chefiar o Departamento de Matemática foi o professor e matemático Francis Dominic Murnaghan, que teve como colaboradores para organizar o quadro docente deste departamento os professores Francisco Antonio Lacaz Netto e Flávio Botelho Reis (1913-?), sendo o primeiro escolhido por ser considerado um bom didata e o segundo por ser matemático e pesquisador.

Enfatizamos a importância do professor Lacaz na constituição desse quadro docente, pois convidou profissionais que, posteriormente, contribuíram para a Matemática brasileira. Ou seja, professor Lacaz teve a percepção de convidar pessoas que realmente fizeram a diferença, tanto para a sociedade científica brasileira quanto para o ITA. Estes convidados que compunham o quadro docente, nessa fase inicial do ITA, eram recémformados e alunos de destaque nas instituições que estudavam. Dentre eles destacamos os professores Nelson Onuchic (1926-1999) e Leônidas Hegenberg (1925-2012) ${ }^{10}$, por serem nomes reconhecidos no cenário científico da área da Matemática brasileira.

\footnotetext{
${ }^{8}$ Matemático Irlandês cuja área de atuação era tanto em Matemática Pura quanto Aplicada, especificamente em Equações Diferenciais e Teoria de Representações de Grupo. Iniciou sua carreira docente no Instituto de Rice, em Houston, Texas e, posteriormente, na Universidade de Johns Hopkins. Foi convidado para ser o primeiro professor de matemática do ITA, onde aposentou-se e, depois, retornou aos Estados Unidos.

${ }^{9}$ No contrato consta que o professor contratado tem o direito de casa ou apartamento mobiliado, no Centro Técnico de Aeronáutica, livre de aluguel ou taxas.

${ }^{10} \mathrm{O}$ professor Leônidas foi o primeiro a ser convidado pelo professor Lacaz e começou a trabalhar no ITA logo após se formar em Física e Matemática pela FFCL do Instituto Mackenizie. Foi importante para divulgação da Lógica no Brasil. Já o professor Nelson Onuchic foi convidado por Lacaz ainda cursando Física no Mackenzie, pois era considerado um aluno de destaque. Seus trabalhos na área de Equações Diferenciais contribuiu para que se iniciasse no Brasil uma área de pesquisa de Equações Diferenciais com Retardamento.
} 


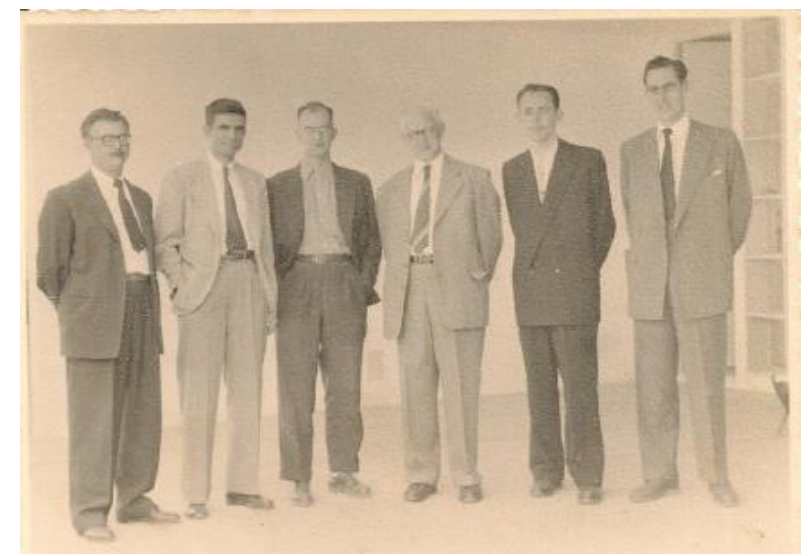

Figura 4: Departamento de Matemática (década de 1950): da esquerda para direita: Francisco A. Lacaz Netto, Flávio Botelho Reis, não identificado, Francis D. Murnaghan, Nelson Onuchic, Leônicas Hegenberg

(Acervo Pessoal Prof. F. A. Lacaz Netto)

Professor Lacaz sentia-se honrado em poder fazer parte da história deste departamento e de auxiliar o professor Murnaghan, pois de acordo com ele próprio

“[...] quero render, publicamente, minhas homenagens de admiração $e$ simpatia intelectual, ao ilustre Prof. Francis Murnaghan - homem de inteligência e princípios, a quem tive a honra de ajudar na formação do Departamento de Matemática, do Instituto [...]." (Informação Verbal.) ${ }^{11}$

Professor Murnaghan permaneceu como chefe e professor do Departamento de Matemática do ITA até 1959, quando retornou aos Estados Unidos. Neste sentido, professor Lacaz o substitutiu, exercendo o cargo de chefe do Departamento de Matemática no período de 1962 a 1965.

Afastou-se da chefia em 1966 quando assumiu a reitoria do ITA, permanecendo nesta função até 1973. Mesmo reitor, não deixou a sala de aula, continuou lecionando. Após o término de suas atividades na reitoria, retornou de vez às suas funções de professor e tornou-se Professor Titular. Trabalhou no Departamento de Matemática até sua aposentadoria em 07 de fevereiro de 1981. Neste mesmo ano, em 19 de fevereiro, na 243 Reunião da Congregação dos Professores do ITA foi-lhe concedido o título de Professor

${ }^{11}$ Discurso de paraninfo encontrado no Acervo Pessoal Prof. F. A. Lacaz Netto. 
Emérito, aprovada por unanimidade. Mesmo aposentado comparecia ao ITA como professor conferencista, auxiliando os alunos.

Lacaz Netto foi uma figura de destaque para o Departamento de Matemática do ITA, principalmente com relação à sua criação e constituição. Empenhou-se para formar um departamento de qualidade, convidando pessoas capacitadas. Além disso, realizou o magistério com prazer e uma de suas principais características era o quanto compreendia os alunos. No próximo item, relataremos uma de suas peculiaridades que era esta relação estreita que tinha com seus alunos.

\section{Os alunos}

“Às vezes, receio ter inveja dos moços de hoje: da oportunidade de participarem da construção de um mundo novo, mas venço a fraqueza, e peço aos Céus, sejam eles dignos do trabalho que os espera e da grandeza dos dias que irão viver".

- Francisco Antonio Lacaz Netto

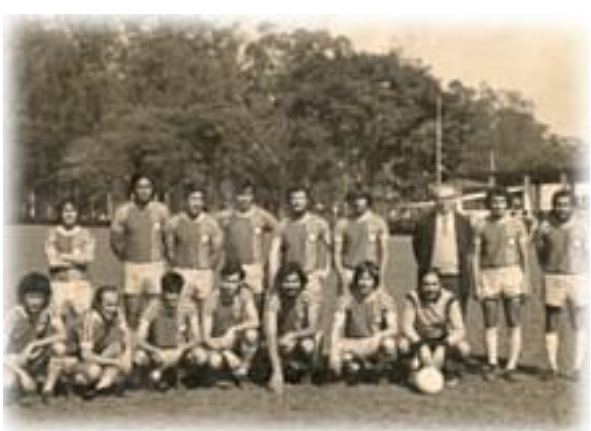

Figura 5: Prof. Lacaz Netto (treinador) e o time de futebol do ITA (sem data) (Acervo Pessoal F. A. Lacaz Netto)

Lacaz Netto realizava com satisfação o seu papel de professor, pois se preocupava com o aprendizado dos alunos e por isso era considerado, entre seus colegas, um grande educador, procurando ensinar a partir da participação dos alunos em sala. Não descansava enquanto todos não tivessem entendido o conteúdo apresentado.

Outra característica do professor Lacaz era de estar sempre do lado do aluno, independente da situação em que este se encontrava. Professor Lacaz ouvia primeiro o aluno e depois o professor da disciplina. Os alunos o estimavam e admiravam-no tanto que esse foi um dos motivos para ser escolhido como reitor do ITA, indicado pelo então diretor do CTA, um de seus ex-alunos.

Constatamos todo esse apreço em depoimentos e correspondências e enfatizaremos dentre estes depoimentos, uma carta do professor Leônidas, que foi seu aluno na FFCL do Mackenzie, da qual relevamos o seguinte trecho

"Não me esqueço, professor Lacaz, da lição de humildade que V. Mafcia, nos deu na FFCL do Mackenzie, nos idos de 1947/48, ao dizer que a esperança do mestre é a de ver seus discípulos progredirem asseverando que a grande alegria do professor é constatar que seus alunos se beneficiam dos ensinamentos recebidos e passam, por seu turno, a incentivar os que com eles convivem. Não me esqueço, ainda, de que foi V. Mafcia, quem confiou em mim, trazendo-me para o ITA. Não 
me esqueço de que foi graças ao seu estímulo que fui capaz de superar os naturais percalços que se colocaram diante de mim nos primeiros anos de magistério. Não esqueço do exemplo de V. Mafcia sempre foi - como uma das mais notáveis figuras humanas que conheci". (Informação Verbal.) $)^{12}$

Além desta declaração, verificamos a admiração dos alunos em uma homenagem concedida pela Associação dos Antigos Alunos do ITA (AAAITA), com o título de Sócio Honorário. Foi o único professor do ITA a obter este título e o recebeu na Solenidade de Formatura da Turma de 1975, que na ocasião os alunos proferiram um discurso e evidenciamos a seguinte parte:

"Na qualidade de representante da Associação dos Antigos Alunos do ITA venho, com muita satisfação e extremamente honrado, anunciar de público nesta solenidade, o nome do nosso mais recente Sócio Honorário que é o ilustre Prof. Francisco Antonio Lacaz Netto, eleito que foi pela unanimidade de nossos associados.

$[\ldots]$

O que ocorreu na eleição do Prof. Lacaz, verdadeiramente, foi a súbita explosão de todo até então contido reconhecimento dos antigos alunos ao querido mestre por esses anos todos de convívio, quando, por seu exemplo e por suas palavras, fomos sistematicamente estimulados $e$ compreendidos, orientados e chefiados, advertidos e repreendidos até, dependendo do nível de carga de sua bateria emotiva...

o Prof. Lacaz se nos afigura como a personalidade polivalente, profundamente humana e sensivel a todos, em contínua comunhão com o Bem Maior, buscando em si a síntese do todo, jamais se apegando a apenas algumas das múltiplas faces da verdade global - pois se ora ele se reveste das feições de professor, ora também é o companheiro esportista, apitador de jogos de futebol, torcedor declarado do São Paulo F.C. e o grande vibrador pelo nosso aeroclube - se ora é o transmissor de conhecimentos puramente técnicos, ora também é o mal disfarçado botânico e o cultivador das roseiras do ITA, se ora é conselheiro amigo, ora também é o Chefe, indignado com excesso dos trotes nos calouros. Em tudo porém se identificando com o grande Educador que é, em sua mais autêntica, legítima e profunda vocação." (Informação Verbal.) ${ }^{13}$

Por meio deste discurso, constatamos que Lacaz Netto não apresentava aos seus alunos uma imagem somente de professor, mas de amigo e conselheiro, daquele que fazia parte da rotina dos alunos, não ficando só papel de dever cumprido dentro da sala de aula.

12 Acervo Pessoal Prof. F. A. Lacaz Netto. Refere-se a carta do professor Leônidas ao professor Lacaz Netto datada de 25 de março de 1971.

${ }^{13}$ Acervo Pessoal F. A. Lacaz Netto.

RBHM, Vol. 16, n 32, p. 1-17, 2016 
Para os alunos, o professor Lacaz era muito mais. Era o treinador, o companheiro, o amigo. Assim, finalizamos uma pequena parte do que foi a relação aluno/professor e destacamos um artigo de autor desconhecido publicado no Suplemento Interno do ITA $^{14}$, do ano de 1954, sobre uma aula lecionada pelo professor Lacaz, cujo tema era o Teorema de Dirichlet. A partir deste artigo conheceremos uma possível imagem que os alunos faziam sobre sua aula e uma das características de sua didática:

\begin{abstract}
"ENUNCIADO DO TEOREMA DE DIRICHLET
Seja $f$ um vetor - o quê? - um vetor-função. Preste bem atenção - não copie agora, depois eu repito novamente - definido no intervalo $\left[x_{1}, x_{2}\right]-$ não é verdade? E se um ponto x qual - o quê? - qualquer função é deri o quê? - derivável à direita e à esquerda - note que eu não sei se a funo quê? - função é derivável no ponto - não me interessa - preste bem atenção - e o valor da deri - o quê? - derivada à esquerda e à direita podem ser desi - o quê? - desiguais. Pois bem, a série de Fourier que lhe é associ - o quê? - associada, no sistema exponen - o quê? - exponencial - note que presta bem atenção, só vale para o sistema exponen - o quê? exponencial, não é verdade? Preste bem atenção, a série de Fourier tem como soma neste - o quê? - neste ponto a média aritmética dos valores que a fun - o quê? - função assume imediatamente à esquerda e à direi o quê? - direita do ponto - o quê? - do ponto $x$. Note que não há dificuldade alguma, não é verdade? - coisa muito fácil - não é mesmo Sattelmayer? Repita o enunciado - vão estudando, vocês estão aqui para estudar - vamos Sattelmayer! - note que a demonstração é uma vergonheira, só fazer continhas, não é verdade? Matemática é sempre a mesma xaropada; - Sattelmayer?! (É a vez do Sattelmayer...)” (SOARES, 2012, p. 57).
\end{abstract}

Neste artigo, observamos os exagerados “o quê?" colocado pelo autor, mas professor Lacaz pretendia, a partir disto, incentivar a participação dos alunos em sala de aula, principalmente, levá-los à lousa, como se nota nos últimos parágrafos do artigo. Com isso, pudemos idealizar uma das aulas lecionadas pelo professor Lacaz na década de 1950 e que não diferenciam das aulas de períodos posteriores.

Apresentamos, dessa maneira, uma parte do que foi Francisco Antonio Lacaz Netto como professor e o que representou para o ITA e para seus ex-alunos. Além de professor foi amigo, conselheiro e técnico de futebol, destacando-se como um dos professores mais queridos do instituto. Além desses atributos, professor Lacaz também era apaixonado pela Matemática e, neste sentido, apresentaremos, sucintamente, a seguir, os trabalhos que elaborou durante sua trajetória de vida.

\footnotetext{
14 Jornal informativo de circulação interna do Instituto, editado pelos alunos.
} 
Os Trabalhos ${ }^{15}$

"No Brasil, atualmente, uma das falhas do ensino nos Colégios e Escolas Superiores, é a falta de compêndios onde o aluno encontre a matéria exigida nos programas oficiais.

A, meu ver, esse mal seria sanado, si todo professor publicasse suas lições, em forma de apostilas ou livros, ampliados de publicação em publicação".

- Francisco Antonio Lacaz Netto

Apesar de não ter produzido nenhuma teoria matemática, Professor Lacaz publicou vários livros didáticos dedicados ao Ensino Básico, o que nos faz concluir o seu interesse pela educação e, por gostar de Matemática, também elaborou alguns trabalhos matemáticos.

Nos trabalhos que professor Lacaz publicou na parte de Matemática, destacaremos um artigo intitulado Considerações sobre uma Equação Diofantina, por ter sido publicado no $1^{\circ}$ volume do $1^{\circ}$ fascículo do Boletim da Sociedade de Matemática de São Paulo, de junho de 1946. Tal artigo apresenta características da área da Teoria dos Números.

Outro destaque que relataremos neste artigo são as publicações de livros didáticos. Estes livros foram elaborados nos períodos das Reformas Gustavo Capanema (1942-1950) e Simões Filho (1951-1966) e eram propostos ao Ginásio e aos Cursos Clássico e Científico. Nessas reformas, principalmente na primeira, constatamos considerável produção bibliográfica deste professor que, junto com outros autores de livros didáticos dessa mesma época, como José Abdelhay, Benedicto Castrucci, Euclides Roxo, evidenciaram, com as suas obras, suas participações no processo de constituição da disciplina Matemática do Ginásio (OTONE e SILVA; RIBEIRO, 2007). Nesse sentido, os livros produzidos pelo professor Lacaz foram relevantes para a História da Educação Matemática brasileira, especialmente para o desenvolvimento e o surgimento da disciplina Matemática no Ensino Básico. Ou seja, Lacaz Netto, a partir de suas obras, pode ser considerado uma personagem da História da Educação Matemática do Brasil.

Suas produções também possuíam outras finalidades e uma delas era a de alcançar os alunos, auxiliando-os na matéria exposta, tanto para os que gostavam de Matemática como os que se preparavam para determinados exames. Nesta perspectiva, realizaremos, a seguir, uma relação de sua bibliografia didática, a saber:

- Exercícios de Vetores: São Paulo: Editora Clássico Científica S/A. 1942.

- $\quad$ Formas e Equações Lineares. São Paulo: Editora do Brasil. 1944.

- Lições de Análise Combinatória. São Paulo: Editora Clássico Científica S/A. 1943. Primeira Edição (foram publicadas até a sétima edição pela Livraria Nobel S/A, São Paulo).

- Lugares Geométricos Planos. São Paulo: Editora Bandeirantes. 1951 - Primeira Edição.

15 Para este artigo listaremos somente alguns dos trabalhos publicados pelo professor Lacaz, para mais informações ver CALABRIA, 2015.

RBHM, Vol. 16, n 32, p. 1-17, 2016 
- Complemento sobre Vetores. São Paulo: Livraria Nobel S/A. 1957.

- Teoria Elementar dos Determinantes. São Paulo: Editora Clássico Científica S/A.1943. Primeira Edição (a terceira edição foi publicada em 1954, pela Editora Bandeirantes, e a quarta edição, em 1958, pela Livraria Nobel).

- Trigonometria. São Paulo: Editora Bandeirantes. 1954. Primeira Edição (a terceira edição foi publicada pela Livraria Nobel em 1963).

- Matemática $\left(1^{\circ}, 2^{\circ}, 3^{\circ}\right.$ e $4^{\circ}$ volumes) - Curso Ginasial. São Paulo: Livraria Francisco Alves. 1958. Com a colaboração do Professor Willie A. Maurer.

- Números Reais. São Paulo: Livraria Nobel S/A. 1958.

Além desses livros didáticos, Lacaz Netto fez outras publicações de aspectos educacionais e de grande interesse para este artigo, os quais são livros com temas relacionados à História da Matemática, especificamente, biografias. Este trabalho possui dois volumes e tem como título Pequena História - Grandes Matemáticos, publicado pela Equilab S/A, São José dos Campos, com o qual professor Lacaz pretendia que seus leitores encontrassem incentivo para seus estudos e, principalmente, conhecer sobre as dificuldades encontradadas pelos matemáticos no decorrer de suas vidas. Professor Lacaz lecionou por duas vezes a disciplina História da Matemática no Departamento de Humanidades do ITA e apreciava esta disciplina. Além disso, na maioria de seus trabalhos apresentava um breve histórico sobre o assunto tratado.

Outro trabalho que gostaríamos de destacar, foi uma publicação própria, a qual dedicou a maior parte de sua vida e a considerava um desafio. Tal trabalho refere-se à tentativa de demonstração do "Último Teorema de Fermat". Professor Lacaz elaborou duas demonstrações, uma em 1985 e outra em 1991. A primeira demonstração foi puramente diofantina e a segunda foi aprensentada no campo racional, ou seja, utilizou de ferramentas da Teoria dos Números. Com isso, gostaríamos de enfatizar a sua excentricidade ao tentar demonstrar este teorema, mostrando o quanto gostava de Matemática e o quanto poderíamos aprender ao procurar entender sua demonstração ${ }^{16}$.

Com a exposição desses trabalhos elaborados pelo professor Lacaz pudemos destacar a sua colaboração com a bibliografia matemática brasileira.

E para finalizarmos apresentaremos, dentre as muitas homenagens recebidas, uma que consideramos de destaque para ser incluída nesta breve biografia, no sentido de mostrar o prestígio do professor Lacaz dentro da comunidade civil e acadêmica. Esta homenagem foi concedida pelo ITA denominada Láurea "Professor Lacaz Netto", que tem por objetivo incentivar a realização de trabalhos de alto nível por alunos do ITA e como reconhecimento do seu antigo professor Francisco Antonio Lacaz Netto foi instituído, a partir de 1996, esta Láurea que recebe o nome de nosso biografado.

Não podemos deixar de enfatizar também que participou de algumas sociedades científicas como a Sociedade Matemática de São Paulo, da qual foi membro e um dos sócios fundadores, com o cargo de Secretário Auxiliar e, também, participou, dentro desta sociedade, de uma comissão para discutir assuntos didáticos, com o objetivo de melhorar o

${ }^{16}$ Mais informações sobre esse trabalho do professor Lacaz pode ser encontrado em CALABRIA, 2015. 
ensino secundário e estudar questões relativas ao ensino de Matemática (TRIVIZOLI, 2008).

Assim, este artigo procurou trazer para à comunidade acadêmica e à História da Matemática do Brasil mais uma personagem, através de uma breve biografia, destacando nela alguns aspectos de sua trajetória de vida como o seu papel de professor e educador matemático, apresentado por meio dos seus livros didáticos, ou seja, aquele que foi preocupado com o ensino de Matemática, e, principalmente, o seu destaque dentro do Instituto Tecnológico de Aeronáutica, especificamente, no Departamento de Matemática.

\section{Considerações Finais}

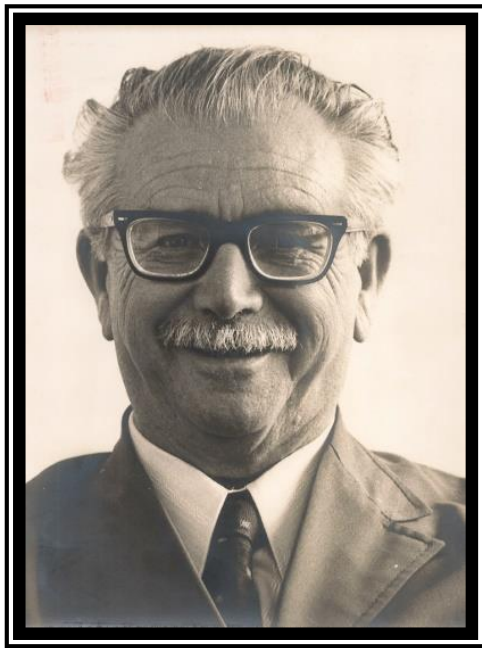

Figura 6: Francisco Antonio Lacaz Netto (sem data) (Acervo Pessoal Prof. F. A. Lacaz Netto)

Este professor não foi criador de escola matemática, não elaborou nenhuma teoria e nem realizou muitos trabalhos na área de Matemática Pura e Aplicada, mas foi uma pessoa importante para a Educação Matemática e para o Departamento de Matemática do ITA. Na Educação Matemática colaborou com a produção de vários livros didáticos direcionados ao Ensino Básico e, também, se preocupava com uma das missões do professor, que é garantir o aprendizado do aluno; por isso, muitas vezes, era considerado entre os colegas o "grande didata". Outras características a serem evidenciadas como educador eram a amizade e atenção que possuía pelo corpo discente e, em consequência disso, recebeu várias homenagens exclusivas por estar tão próximo dos alunos. Já com relação ao Departamento de Matemática, além de professor, também colaborou com a criação deste Departamento, recrutando professores para compor o quadro docente. Destacamos, também, a sua participação como reitor do ITA, a qual foi exercida distintamente no período de sua gestão. Por outro lado, era apaixonado pela matemática, o que pudemos constatar em alguns de seus estudos e trabalhos.

Desta forma, concluímos que professor Lacaz é personagem da História da Matemática brasileira e que é fundamental as informações biográficas apresentadas neste artigo, pois

"[...] interessa não apenas a história de famosos matemáticos, mas também a daqueles professores - mesmo que não produtores de novidades na Matemática - e autores de livros didáticos que desempenharam um papel relevante porque contribuíram para a divulgação do conhecimento e, portanto, como docentes, auxiliaram na 
formação intelectual de milhares de indivíduos" (SAD, SILVA, 2008, p. 43).

Assim, o encerramento deste artigo será realizado pelo próprio professor Lacaz Netto, por meio de uma declaração sobre o que é educação e ser educador, a qual diz o seguinte

Não se educa sem uma filosofia de educação, sem um ideal de educação, orientados por um conceito integral da existência.

A educação pode ser considerada transmissão de vida, por seres vivos, a seres vivos.

E por ser a educação um processo vital, a personalidade do educador é de suma importância na obra educativa.

Não é o que o professor sabe ou ensina, sugere ou impõe, que tem grande valia, mas aquilo que está no mais profundo de seu íntimo. O estado de espírito do educador, suas convicções, sua maneira de viver, permanecem, conscientemente ou não, na alma dos discípulos.

Nada, tão magnética e necessariamente, atrai uma pessoa para o bem, do que atitudes claras de um homem de bem, na prática do bem.

Isto que estou dizendo, não se aplica somente na educação do caráter, mas ainda no desenvolvimento da inteligência. O homem, no mestre, constitui o grande poder formador; sua personalidade é o segredo de uma educação fecunda.

E que Deus proteja a todos nós

Era o que desejava dizer

- Francisco Antonio Lacaz Netto.

\section{Bibliografia}

ACERVO Pessoal Prof. F. A. Lacaz Netto

BARALDI, I. M. Retraços da Educação Matemática na Região de Bauru: uma história em construção. 240 f. Tese de doutorado. Instituto de Geociências e Ciências Exatas (IGCE) - Unesp - Rio Claro. 2003.

CAlABRIA, A. R. Francisco Antonio Lacaz Netto (1911-1991): um estudo biográfico. 205 f. Tese de doutorado. Instituto de Geociências e Ciências Exatas (IGCE) - Unesp - Rio Claro. 2015.

GOFF, J.; LE ROY LADURIE; E. Lisboa: Teorema. 1986.

INSTITUTO Tecnológico de Aeronáutica. Instituto Tecnológico de Aeronáutica - ITA: 50 anos (1950 - 2000). São José dos Campos, SP, ITA: ITA, 2000.

ORIEUX, J. A arte do biógrafo. In: História e Nova História. ARIES, P..; DUBY, G.; LE SAD, L. A.; SILVA, C. M. S. Reflexões Teórico-Metodológicos para Investigações em História da Matemática. Bolema. Ano 21. N. 30. p. 27- 46. Rio Claro: 1998.

OTONE e SILVA, M. C.; RIBEIRO, D. F. C. Uma História da Matemática Escolar do Ensino Médio. Coleção História da Matemática para Professores. Orgs: Edilson Roberto Pacheco, Wagner Rodrigues Valente. Guarapuava: SBHMat, 2007. 
SOARES, A. P. Histórias para Contar, Amigos para Encontrar. São José dos Campos, SP: ITA/CTA. 2012.

TEIXEIRA, I. S. dr. F. A. Lacaz Netto mestre por excelência. Informativo da Associação dos Pioneiros e Veteranos da Embraer - APVE. São José dos Campos, ano 8, n. 20, maio-junho/96, p. 8.

TRIVIZOLI, L. M. Sociedade Matemática de São Paulo: um estudo histórico institucional. 2008. 200 f. Dissertação (mestrado). Universidade Estadual Paulista Instituto de Geociências e Ciências Exatas - Rio Claro: 2008.

\section{Angelica Raiz Calabria}

Centro Universitário Hermínio Ometto UNIARARAS - Brasil

E-mail: angel_raiz@yahoo.com.br 